\title{
LA POÉTICA DEL RETRATO: DON QUIJOTE Y LOS MERCADERES TOLEDANOS
}

La presente comunicación se integra en una línea de trabajos más amplia que tiene por objeto el estudio de la representación de la figura femenina en el Quijote de 1605 . Hecho, entonces, este deslinde previo, conviene, pues, precisar aquellos elementos que tornan significativo el análisis de la aventura de los mercaderes toledanos para nuestra labor.

Una vez armado caballero y a lo largo de la primera y segunda salida, Don Quijote pone a prueba en cada una de sus aventuras, a la par de "el valor de (su) brazo" ${ }^{1}$ y de sus nobles intenciones, el modo de ser en el mundo de los distintos personajes con los que se encuentra.

Virtual eṕlogo de la primera salida, el incidente con los mercaderes toledanos se torna significativo no por aquellas características que, desde el punto de vista narrativo, comparte con el resto de las aventuras - ya que éstas hacen hincapié en la homogeneidad del conjunto ${ }^{2}-$ sino, por el contrario, por el diverso grado de adecuación de la experiencia a la prefiguración mental de lo que Don Quijote considera una aventura.

Tal como lo ha hecho manifiesto en el fundacional primer capítulo, toda aventura ideal tendría por objeto la derrota de un

II, 18, p. 126.

2 Me hago eco de la distinción que la critica ha hecho entre aventura, episodio y novela intercalada. Quien esté interesado en estas temáticas puede consultar RAYMOND IMMERWAHR, *Structural Symmetry in the episodic narratives of Don Quijote», Comparative Literature, 10, 1958, 131-135; EDWARD RILEY, «Episodio, Novela y Aventura en Don Quijote», Anales Cervantinos, V, 1955-1956, 209-230. 
gigante malandrín ( $\alpha$ el gigante Caraculiambro» ${ }^{3}$ ) quien iría en calidad de "presentado " ${ }^{4}$ ante la dama y reafirmaría el valor de su amado a través de la mención de su nombre y de las hazañas que ha llevado a cabo.

Este «circuito del nombre» - para retomar la denominación pautada por la profesora Alicia Parodi-tiende a priorizar un tipo particular de unión entre los amantes - de corte espiritual, no físico- que se logra cuando la persona del caballero se ubica en presencia de su dama a través de la mención de su nombre -situación ésta a la cual se llega por intermedio de un tercero derrotado que, en calidad de penitencia se somete al poder de la dama de su vencedor-. Con todo, y por simple que ello parezca, varios son los aspectos a remarcar.

Un primer punto de interés es el de que el modo de enamorar a Dulcinea que Don Quijote ha elegido se erija en reflejo invertido de su enamoramiento por su dama que, según habrá de confesarlo en la Segunda Parte de la obra, poco precisa del universo material de su persona:

* ¿No te he dicho mil veces que en todos los días de mi vida no he visto a la sin par Dulcinea, ni jamás atravesé los umbrales de su palacio, y que sólo estoy enamorado de oídas y de la gran fama que tiene de hermosa y discreta?. 5

El amor ex auditu contrapuesto culturalmente a la pasión de $v i s{ }^{6}{ }^{6}$ refuerza, en primer término, la problematización de lo corpóreo y, por otra parte, recuerda claramente la ascendencia religiosa del tipo de unión elegida, prefigurada - como bien es sabido- en la fecundación virginal.

Más allá de que sea un hecho confirmado que la poesía de los trovadores y de otras vertientes artísticas adhirieron a los postulados del amor ex auditu, no puede dejar de resaltarse que aquí Cervantes introduce un claro elemento paródico en la construcción de su enamorado caballero.

Como bien lo ha demostrado Jacques Gélis ${ }^{7}$, la sociedad española de los años inmediatamente posteriores a los grandes

${ }^{3}$ I, 1, p. 28.

I, 1, p. 27.

5 II, 9, p. 488.

- Véase el artículo de Francisco Yndurain, «Enamorarse de ofdas” en Serta Philologica F. Lazaro Carreter, Madrid, Cátedra, 1983, tomo II.

7 Véase el artículo de JAcoues Gélis, «L'évolution de la conscience de la vie et du corps en Espagne aux XVI et XVII siècles. La protection de la femme et du nouveau-nex en Agustín Redondo Le corps dans la société espagnole des xVI et XVII siecles, Paris, Publications de la Sorbonne, 1990. 
descubrimientos geográficos tiende a desarrollar, paulatinamente, lo que se dio en denominar «conciencia corporal» y este fenómeno torna impracticable e irrisoria, para el público lector, la paradoja tiempo-espacial que se desprende del amor ex auditu: el de la presencia de la ausencia, supliendo el nombre el referente corpóreo.

Resultan, asimismo, muy sugestivas las implicaciones que se pueden formular a partir de la presencia necesaria de un tercer mediador en el circuito nominal/amoroso.

Esta figura, en primer término, no responde a los estereotipos del alcahuete o de la doncella mediadora con los cuales el público -a partir de las obras del género celestinesco- podía estar muy familiarizado. Su corpórea presencia, en calidad de vencido, era, ante todo, un símbolo de humillación para su persona y constituía una vía expurgativa de sus yerros, mecanismo con el cual, de hecho, se afianzaba la asociación simbólica entre falibilidad y corpóreo.

Resulta claro entonces, en este orden de ideas, que los diversos grados de correcto acatamiento, por parte de los vencidos y de quienes hubieron mercedes gracias a la intervención de Don Quijote, son aquellos aspectos que sirven para apreciar la heterogeneidad del conjunto de las aventuras de camino.

De las doce que la crítica reconoce en la Primera Parte ${ }^{8}$ del Quijote - las primeras tres en la primera salida del héroe y las restantes nueve en la segunda- no puede decirse, en un sentido amplio, que todas ellas se estructuren de un modo uniforme.

Si la quinta aventura - aquella que emprende contra unos frailes benitos y un vizcaíno - tiene una resolución concordante -para Don Quijote- con el hipotético y artificioso circuito del nombre que él ha creado:

-Estaba el vizcaíno tan turbado, que no podía responder palabra; y él lo pasara tan.mal, según estaba ciego Don Quijote, si las señoras del coche, que hasta entonces con gran desmayo habian mirado la pendencia no fueran adonde estaba y le pidieran con mucho encarecimiento les hiciere $\tan$ gran merced y favor de perdonar la vida a aquel su escudero. A lo cual Don Quijote respondió, con mucho entono y gravedad:

-Por cierto, fermosas señoras, yo soy muy contento de hacer lo que me pedís, mas ha de ser con una condición y concierto: y es que este

\footnotetext{
- Aventura de los arrieros (cap. 3); de Andresillo y Juan Haldudo (cap. 4); de los mercaderes toledanos (cap. 4); de los molinos de viento (cap. 8); de los frailes benitos y el vizcaíno (caps. 8 y 9); de los carneros (cap. 18); del cuerpo muerto (cap. 19); de los batanes (cap. 20); del yelmo de Mambrino (cap. 21); de los galeotes (cap. 22); de los cueros de vino (cap. 35); de los disciplinantes (cap. 52).
} 
caballero me ha de prometer de ir al lugar del Toboso y presentarse de mi parte ante la sin par doña Dulcinea, para que ella haga dél lo que más fuere de su voluntad.

La temerosa y desconsolada señora, sin entrar en cuenta de lo que Don Quijote pedía, y sin preguntar quién Dulcinea fuese, le prometieron que el escudero haría todo aquello que de su parte le fuese mandadon?

el conjunto de las restantes resulta divergente por uno $\mathbf{u}$ otro motivo. En cinco de ellas - la de Andresillo y Juan Haldudo, la de los carneros, la del cuerpo muerto, la del yelmo de Mambrino y la de los cueros de vino- la figura de la dama no es mencionada bajo ningún aspecto.

En otras dos - la de los batanes y la de los disciplinantessólo se hace mención de su persona en parlamentos que mantiene con su escudero luego del combate.

En otras dos - la de los batanes y la de los disciplinantessólo se hace mención de su persona en parlamentos que mantiene con su escudero luego del combate.

Sólo en la primera aventura que encuentra en cada salida - la de los arrieros y la de los molinos de viento- se acuerda el caballero de encomendarse - antes de la lid-al favor de su dama.

Frente a la diversidad de este corpus la aventura "de los mercaderes toledanos" resulta ser la única que se estructura como una batalla caballeresca en torno a la belleza de Dulcinea y su supremacía sobre la de otras damas.

Superada una encrucijada y "puesto en la mitad del camino" 10 Don Quijote interrumpe la marcha de quien él cree caballeros andantes con la exigencia de que:

*-Todo el mundo se tenga, si todo el mundo no confiesa que no hay en el mundo todo doncella más hermosa que la emperatriz de la Mancha, la sin par Dulcinea del Toboson ${ }^{11}$.

Pese a que los caminantes coligen que Don Quijote está loco, el altercado se origina por el reparo burlón de un miembro de la comitiva:

*-Señor caballero, nosotros no conocemos quién sea esa buena señora que decís; mostradnósla, que si ella fuere de tanta hermosura como significáis, de buena gana y sin apremio alguno confesaremos la verdad que por parte vuestra nos es pedida ${ }^{12}$

\footnotetext{
9 I, 9, p. 73.

${ }^{10}$ I, 4, p. 43.

"I, 4 , p. 43.

12 I, 4, pp. 43-44.
} 
dichos a los cuales, diálogo mediante, ha de agregarse una nueva y ofensiva réplica del mercader:

«(...) suplico a vuestra merced en nombre de todos estos príncipes que aqui estamos que, porque no encarguemos nuestras conciencias confesando una cosa por nosotros jamás vista ni óda, y más siendo tan en perjuicio de las emperatrices y reinas del Alcarria y Estremadura, que vuestra merced sea servido de mostrarnos algún retrato de esa señora, aunque sea tamaño como un grano de trigo; que por el hilo se sacará el ovillo, y quedaremos con esto satisfechos y seguros, y tan de su parte que, aunque su retrato nos muestre que es tuerta de un ojo y que del otro le mana bermellon y piedra azufre, con todo eso, por complacer a vuestra merced, diremos en su favor todo lo que quisiere ${ }^{13}$.

Ante tales afirmaciones, vale la pena recordar que - desde la optica de Don Quijote- la prueba a la cual pretende someter a estos "caballeros" no es propia de los amores de visu:

«Si os la mostrara - replicó Don Quijote-, ¿qué hiciérades vosotros en confesar una verdad tan notoria? La importancia está en que, sin verla, lo habéis de creer, confesar, afirmar, jurar y defender» ${ }^{14}$.

Plegada en dos partes, entre una interrogación retórica -cuyo fin es negar una prótasis condicional- y una afirmación conclusiva, la réplica de Don Quijote tiende a precisar la improcedencia de la percepción sensible y la fe militante que informa su vida.

Sobre esta última, cabe precisar que su presentación, cual máxima categórica exigible a todos por igual, depende, en gran medida del entramado retórico de los verbos en infinitivo de esta frase.

Opuestos en dos grupos claramente discernibles a partir de una articulación quiásmica desigual en sus partes, el «verla» del inciso concesivo que implica una percepción sensible ha de oponerse a la perifrasis verbal con cinco infinitivos dependientes.

La gradatio establecida por medio de la progresión acreer, confesar, afirmar, jurar y defender no es arbitraria desde ningún punto de vista. Mientras el primer elemento de la serie traduce una acción personal de sesgo reflexivo interior, no necesariamente social -opuesto en este sentido a los otros cuatro infinitivos que presuponen una segunda persona-, el término final ( $\propto$ defender ) implica, en un sentido recto, un obrar que no se realiza, prioritariamente, a través de las palabras - tal como sucede en los tres infinitivos pragmáticos centrales-.

${ }^{13}$ I, 4, p. 44.

14 I, 4, p. 44. 
Si la manifestación de la interioridad se plasma a través del eje creer/defender, la reubicación de Dulcinea en un absoluto - violentamente degradado ante la exigencia de pruebas concretas-habrá de realizarse por medio del contraste de los pronombres constitutivos del quiasmo.

Mientras el "la» enclítico sólo podría tener por referente a una Dulcinea real, la predicación exigida a esta egente descomunal y soberbia" ${ }^{15}$ presenta un carácter unitivo y absoluto reforzado por la forma pronominal objetiva neutra («lo») que, a la sazón, opera como término no marcado y que impide la escisión individuante entre esencia y predicación.

El segundo embate verbal del mercader toledano ha de importarnos, en primer lugar, porque retoma los postulados significativos y argumentativos del caballero andante en aras de una burla más ácida.

Si Don Quijote ha renegado de la percepción sensible a través del reconocimiento interior, la única sabiduría interna que el mercader retoma -en aparente línea espiritual- es la de un supuesto caso de conciencia.

No sólo se reúnen en un pie de igualdad las bellezas vistas y las oídas -recuérdese el confronte polémico de la época en torno a los dos sentidos- sino que también se esgrimen identidades hipotéticas («emperatrices y reinas del Alcarria y Estremadura") en cuyo perjuicio se accedería a lo solicitado.

Toda la «súplica" del mercader denota un progresivo avance del interlocutor sobre la construcción simbólica de Dulcinea. Si aducir la existencia de otras reinas y emperatrices sólo apunta a relativizar el valor intrínsico de la dama sin par, la petición del retrato - por las características del mismo e índole de lo representado- ha de transformarse en una degradación de aquélla y de quien posee este objeto.

La solicitud del retrato de Dulcinea traslada el confronte en torno a su belleza suprema a dos aspectos simbólicos que se complementan.

El primero de ellos es el que se articula entre los polos público/privado. Tal como lo ha demostrado Carlo A. Ginsburg ${ }^{16}$ la representación erótica en los siglos XVI y XVII europeos conoce dos tipos de circuitos icónicos privilegiados: el social de los grandes frescos - sobre los cuales, prioritariamente, centraba sus

\footnotetext{
15 I, 4, p. 44.

16 Véase el libro de Carlo A. Ginsburg, Mitos, Emblemas, Indicios, Morfología e historia, Barcelona, Gedisa, 1989, particularmente el capitulo denominado «Ticiano, Ovidio y los códigos de la representación erótica en el siglo xvi».
} 
embates la siempre fiel y vigilante iglesia- y el individual construido por obras de dimensiones reducidas.

En este orden de ideas, no puede pasarse por alto la especulación que realiza el mercader de que el retrato sea "tamaño como un grano de trigo". La irrisoria hipótesis de que pueda existir un retrato de esas dimensiones opera - a través de las asociaciones simbólicas del "grano de trigo" - como una vía negativa por la cual se ataca a la dama.

De ascendencia diversa y, sin embargo, concordantes, dos son las tradiciones que otorgan al grano de trino un vínculo estrecho con lo sagrado. En primer lugar hay que tener presente que en los rituales paganos de culturas agrarias de la antigüedad, la exhibición de un grano de trigo a un iniciado constituía lo que los cultores de los misterios de Eleusis denominaron epoptika, aquella instancia en la cual se revelaba a un nuevo miembro el ordo sacro. El grano de trigo que nace, muere y renace, operaba cual cifra de la génesis $\mathrm{y}$, paralelamente, era considerado como un don de la divinidad a los humanos.

En este sentido, también debe recordarse que, ya no en el paganismo, sino en el seno mismo de la cultura cristiana, la parábola de la cizaña en medio del trigo (Mateo 13, 24-30), sirve para oponer dos clases de hombres, la de aquellos que han oído la llamada del Reino y la de quienes sólo han atendido al diablo.

Se ve, entonces, claramente, cómo la burla del mercader no se articula, unívocamente, sobre la profanación contemplativa que supondría la exhibición - por parte de Don Quijote- del retrato de la dama a un tercero que, en principio, no estaría facultado para observarlo y gozar con él.

Si la primera alternativa haría de Dulcinea una mujer pública, la segunda, a través de la imposible existencia de un retrato "tamaño como un grano de trigo" vedaría la asociación simbólica de esa mujer con las criaturas del Reino.

Mientras que el primer aspecto polémico de las palabras del mercader se organiza a partir de las dimensiones del retrato, el segundo de ellos atiende, muy atentamente, al proceso de la mímesis y al referente representado.

Si se descartan las figuras de las mozas del partido en la primera venta que Don Quijote visita (I, 2), cuya caracterización negativa corre por cuenta del narrador, se notará, puntualmente, que este altercado con el mercader toledano es el primer momento en que la esencia femenina, sublimada por el dinamismo creador de sus palabras en el primer capítulo, se ve obligada a ser fijada en una representación estable y pictórica. 
Pero éste, no es el único aspecto importante que supone la existencia de una imagen visual de Dulcinea. Al no cuestionarse la estética que guía la mímesis y quedar, por ende, descartada, la posibilidad de que el retrato imaginado por el mercader sea grotesco, el realismo como criterio de representación invierte los modos de acceso a la esencia de Dulcinea y, consecuentemente, de la mujer.

El debate sobre la representación de la dama deviene, en la mente de Don Quijote, en una polémica sobre la predicación de una esencia.

Lejos, muy lejos, de los estereotipos petrarquistas para la belleza femenina, el mercader llega a suponer que la dama de Don Quijote puede ser «tuerta de un ojo y que del otro le mana bermellón y piedra azufre". Tal hipótesis unida a la afirmación subsiguiente de que «por complacer a vuestra merced, diremos en su favor todo lo que quisiere» implica no sólo, una relativización burlesca del caso de conciencia previamente enunciado, sino también la manifestación objetiva de que se cree loco a Don Quijote.

No puede dejar de notarse que, si se acepta un criterio realista en la construcción del retrato solicitado, la figura de Dulcinea se acercaría más a un emblema de la no femineidad.

En este implícito debate sobre la esencia femenina, no es casual que la degradación de la dama quede cifrada en sus ojos. En eco lejano, la carencia de un ojo en el retrato de Dulcinea, cual si de una cíclope subhumana se tratara, torna aún más irrisoria la afirmación previa de Don Quijote de que su dama es «sin par».

Con todo, si se acepta que es también éste un debate sobre la esencia, resultan altamente significativos los dichos de dos evangelistas. Mateo $(6,22-23)^{17}$ al igual que Lucas $(13,34-36)^{18}$ nos aclaran que los ojos son la puerta del alma y que, consecuentemente, el ojo sano es el de quien ha recibido en su interior la luz del Señor y que, contrariamente, el enfermo es indicativo de aquél que se guía por la luz de las tinieblas.

La mención del «azufre», manando de un único ojo, debe ser

17 *22. Lámpara de tu cuerpo son tus ojos. Si tu ojo, pues, es limpio, todo tu cuerpo estará iluminado. 23. Más si tu ojo está enfermo, todo tu cuerpo estará obscurecido. Pues si la luz que hayen en ti son tinieblas, ¡cuántas tinieblas habra!»

18 *34. Lámpara de tu cuerpo son tus ojos. Si tu ojo fuere puro todo tu cuerpo estará iluminado más, si fuere malo, también tu cuerpo estará lleno de tinieblas. 35. Cuida, pues, de que la luz que hay en ti no sea de tinieblas. 36 . Porque si tu cuerpo estuviere todo iluminado, sin tener parte alguna obscura, todo él estará iluminado, como cuando la lámpara te ilumina con vivo resplandor». 
leída, asimismo, desde una perspectiva religiosa. Pues, si bien puede ser relevante que el esoterismo y la alquimia de la época vean en él el correlato mineral de la esperma, no puede olvidarse que, para los cristianos, la connotación es mucho más pecisa. Azufre y fuego llovió Dios sobre Sodoma y Gomorra, de azufre es la luz de las tinieblas.

Con respecto al "bermellón" sólo cabría agregar, siguiendo a Covarrubias, que este producto se asocia a los gusanos, claro signo de putrefacción.

La carencia de belleza, articulada como el vacío de un ojo y la enfermedad del restante - con lo cual se obstruye, en los parámetros del amor de visu, el reconocimiento del otro- implica, asimismo, la degradación moral de Dulcinea desde una perspectiva histórica.

La fealdad - como bien lo han hecho público los estudios sobre la realidad de la mujer en la época- ${ }^{19}$ era, en todo sentido, un estigma difícil de sobrellevar, una mácula que indicaba, a quien quisiera verlo, la vileza del ser.

En el horizonte prostibulario y de las enfermedades y secuelas que este oficio acarreaba, no deja de parecernos importante, como un eco lejano que nos permite comprender todos los alcances violentos que anidan en la petición del retrato, la figura de la protagonista de La lozana andaluza.

Por novel e incipiente que resulte esta veta crítica, es un hecho constatable - más allá de los puntos de contacto sugeridos por la profesora Bubnova ${ }^{20}$ - que tanto Dulcinea y Lozana, la meretriz más importante de Roma en tiempos de Carlos V según Delicado, tienen en común el nombre de Aldonza ${ }^{21}$ y que, asimismo, amén del sinnúmero de mujeres carentes de belleza por los estragos de la sífilis que aquel texto nos presenta, la degradación historial de la protagonista (Aldonza/Lozana/Vellida) encuentra una forma particular de narración en el Retrato ${ }^{22}$. ¿Será, por ventura, este tipo de retrato el que el mercader solicita?

No se olvide, como último detalle de interés, concordante con

${ }^{19}$ Consúltese, en sus diferentes secciones, el estudio colectivo Historia de las mujeres, del Renacimiento a la Edad Moderna, tomo bajo la dirección de Arlette Farge y Natalie Zemon Davis. Madrid, Taurus, 1992.

20 Véase el artículo de Tatiana Bubnova, "Cervantes y Delicado» en Nueva Revista de Filologia Hispánica, Número Monográfico dedicado a Cervantes bajo la dirección de Monique Joly, XXXVIII, 1990, 2, pp. 567-590.

${ }_{21}$ Sobre el nombre Aldonza y su correlato idealizante Dulcinea véase el ya clásico trabajo de RAFAEL LAPESA, «Aldonza-Dulce-Dulcinean en De la Edad Media a nuestros dias, Estudios de Historia Literaria. Madrid, Gredos, 1967.

${ }_{22}$ Sobre los modos correctos de intelección del término retrato véase el estudio preliminar del profesor Allaigre a su edición de la obra. 
esta línea de análisis, que la descripción que el narrador hace de la carnal Maritornes - confundida por Don Quijote con la hija de un señor castellano-, en lo que respecta a la "belleza" de su cara era "del un ojo tuerta y del otro no muy sana" ${ }^{23}$.

Ante este estado de la discusión, la respuesta airada de Don Quijote no se hace esperar:

*-No le mana, canalla infame - respondió Don Quijote encendido en cólera-; no le mana, digo, eso que decís, sino ámbar y algalia entre algodones; y no es tuerta ni corcovada, sino más derecha que un huso de Guadarrama. ¡Pero vosotros pagaréis la grande blasfemia que habéis dicho contra tamaña beldad como es la de mi señora!» ${ }^{24}$

Más allá del fin desastrado que tendrá el combate para Don Quijote, debe retenerse, en esta etapa de análisis, que todo el parlamento de Don Quijote - centrado en la degradación de Dulcinea y excluyendo el problema de su cordura - supone, en los términos del ataque a su figura, un aspecto no formulado por el mercader.

$\mathrm{Si}$, por un lado, la mención de "ámbar y algalia» tiene por fin reemplazar el humillante recuerdo del ubermellón y piedra azufre" manando de un único ojo, y, por el otro, la afirmación "no es tuerta" es una simple contradicción a algo especulado por su adversario, la defensa de su porte no encuentra, en los parlamentos previos, algo que la origine.

Vista de este modo, la afirmación "ni corcovada, sino más derecha que un huso de Guadarrama" obliga al crítico a reponer, en la mente del hidalgo armado caballero, un aspecto conflictivo in absentia, un ataque formulado de un modo implícito.

Traer a colación la rectitud de su figura no sólo permite suponer, en un sentido recto, la belleza integral del resto del cuerpo no figurado en el retrato, sino también, en forma derivada, un aspecto de la conducta de la dama. Aspecto que, por otra parte, se ve reforzado y explicitado en la comparación subsiguiente.

Por más que la expresión "más derecha que un huso de Guadarrama" pueda ser reconocida en su época como muy frecuente, pues las hayas a orillas de este río eran objeto de merecido renombre, no deja de ser notable que, mientras el árbol en el primer capítulo tendía a precisar el tipo de unión indisoluble de dama y caballero, la mención de "un huso" focaliza no sólo un objeto habitual de las tareas cotidianas femeninas, sino tam-

${ }^{23}$ I, 16, p. 112.

24 I, 4, p. 44. 
bién un tipo de actividad propia y representativa del común de las mujeres honestas: ser hilanderas.

Implícitamente, también, Don Quijote ha opuesto a la imagen de la esencia luciferina de la mujer ofrecida por el mercader el de la estereotipada bonomía femenina para la época.

Quien dude de la identificación simbólica «buena mujer = hilandera", puede recordar que cuando el desquiciado Anselmo de El Curioso Impertinente cree que su mujer Camila ya ha resistido a todas las pruebas y se ha convertido en la mujer fuerte, ella es parangonada con las figuras de otras dos hilanderas: Penélope y Lucrecia.

Es muy sugerente, por último, que este vínculo final de Dulcinea con el universo femenino del hilado se vea reforzado - por paradójico que esto pueda parecer- por el parlamento previo del mercader quien, como se recordará, al solicitar el retrato -en tanto prueba concreta de la existencia corporal de Dulcinea- metaforizaba su requerimiento con el dicho de que "por el hilo se sacará el ovillo".

Con todo, e independientemente del final desastrado de la aventura para Don Quijote, resulta importante remarcar - a modo de conclusión - aquellos aspectos que tornan relevante el análisis de esta secuencia narrativa para el estudio de la figura femenina en la novela.

En primer lugar, hay que tener presente que ésta es la primera instancia en la cual se le exigen al caballero pruebas concretas de la existencia de Dulcinea.

En segundo lugar, que la petición de un retrato -propia de los amores de visu - entra en colisión con el enamoramiento ex auditu que anida en el pecho de Don Quijote.

Si se presta atención a la validación del circuito del nombre - como tercer aspecto a retener-cabe afirmar que la pérdida de identidad en la cual Don Quijote queda sumido tras el combate resulta explicable a partir de la ruptura del artificioso circuito en el cual el desdibujamiento de la dama, íntimamente ligada al caballero, repercute en el de su persona ("árbol sin hojas y sin fruto" ${ }^{25}$ ).

Vista desde esta perspectiva, la polémica sobre una hipotética imagen de mujer deja entrever - a partir de la aceptación de un criterio estético realista- dos mentalidades opuestas sobre su esencia presentes en la época.

De todos modos, y no es este un detalle sin importancia, se debe tener en cuenta que el debate - desde las dos encontradas

${ }^{25}$ I, 1, p. 27. 
posiciones - se realiza a partir de la idea de representación que, por paradójico que pueda parecer coinciden en un punto no hecho explícito.

Si la visión del mercader sugiere que la mujer es un ser luciferino en cuyo interior sólo hay tinieblas, la postura de Don Quijote de la dama honesta cual hilandera no alcanza para afirmar la bonomía interna. En este orden de ideas no puede pasarse por alto que la iconografía ofrecida en la época sobre las hilanderas mostraba mujeres sin cabeza - se las habia sorbido la luna- que cumplían con su labor cual autómatas.

Concordantes en la imagen del vacío volitivo, cual seres carentes de alma, cabe decir que el Quijote se propone, en un sentido amplio, la dignificación de esa interioridad ignorada, que, por cierto, no le compete, tan sólo a la mujer.

Es un hecho ampliamente constatado que -a la luz de los episodios intercalados- el texto declara que el reconocimiento del otro como tal es el único camino para saber quiénes somos. De ahí que resulte tan importante la compleja pregunta de quién es y qué quiere la mujer.

\author{
Juan Diego Vila \\ Universidad de Buenos Aires
}

